\title{
Gestão do óleo lubrificante usado em postos de combustíveis no município de Terezópolis de Goiás - GO, Brasil
}

\author{
Management of used lubricating oil in gas stations in the municipality of Terezópolis of Goiás - GO, Brazil \\ Barbbara da Silva Rocha', Paulo Sergio Scalize², Poliana Nascimento Arruda ${ }^{3}$, Karla Alcione da Silva Cruvi- \\ nel $^{4}$ \\ Graduada em Ciências Biológicas, Especialista em Gestão e Planejamento Ambiental, Mestranda em Ecologia e Evolução, Universidade \\ Federal de Goiás, Goiânia, Brasil. \\ ${ }^{2}$ Engenheiro Civil e Biomédico, Mestre e Doutor em Hidráulica e Saneamento, Professor adjunto III na Escola de Engenharia Civil, Profes- \\ sor do Programa de Pós Graduação da Engenharia do Meio Ambiente, Universidade Federal de Goiás, Goiânia, Brasil. \\ ${ }^{3}$ Graduada em Tecnologia em Saneamento Ambiental, Especialista em Tratamento e Disposição Final de Resíduos Sólidos e Líquidos, \\ Mestranda do Programa de Pós-graduação em Engenharia do Meio Ambiente, Universidade Federal de Goiás, Goiânia, Brasil. \\ ${ }^{4}$ Graduada em Engenharia Ambiental, Mestre em Engenharia do Meio Ambiente, Doutoranda em Ciências Ambientais, Universidade \\ Federal de Goiás, Goiânia, Brasil.
}

\begin{abstract}
Resumo
Os postos de combustíveis em geral desenvolvem atividades que geram diversos resíduos, e que necessitam de cuidados especiais em seu destino final. Como exemplos temos o óleo lubrificante usado e suas embalagens que são classificadas segundo norma brasileira como perigosos, devendo ser obedecidas às exigências feitas por resoluções específicas quanto à coleta, tratamento e disposição final. Essa pesquisa objetivou avaliar a gestão do descarte do óleo lubrificante e sua embalagem em postos de combustíveis do município de Terezópolis de Goiás - GO. Foram utilizados questionários estruturados para entrevistas com os responsáveis pelo gerenciamento desses resíduos e foi constatado que apenas 2 postos dos 5 ativos no município realizavam a troca de óleo. Em dois postos analisados o óleo lubrificante usado é coletado por empresa contratada, onde é realizada a reciclagem, porém as embalagens do óleo são destinadas ao aterro controlado do município, sendo tratado como resíduo comum. Nota-se que os postos não cumprem em sua totalidade a legislação, necessitando de fiscalizações e de discussões sobre a importância do tratamento adequado desses resíduos.
\end{abstract}

Palavras-chaves: Gestão ambiental, gerenciamento, óleo lubrificante, postos de combustíveis, resíduos, embalagens.

\begin{abstract}
The gas stations usually develop several activities that generate waste, and require special care in their final destination, as an example we have used lubricating oil and their packaging materials that are classified as hazardous according to Brazilian standard and must be obeyed to the demands made by specific resolutions regarding the collection, treatment and final disposal. This research aimed to evaluate the management of disposal of lubricating oil and its packaging in gas stations in the municipality of Terezópolis of Goiás - GO. Structured questionnaires for interviews with those responsible for managing these wastes and it was found that only two of the five active stations in the municipality performed the oil change were used. Two stations analyzed the lubricating oil is collected by contractor where recycling is conducted, but the packaging of the oil are intended for controlled municipality landfill, being treated as common waste. We notice that the stations do not comply with the legislation in its entirety, requiring inspections and discussion about the importance of proper waste treatment.
\end{abstract}

Keywords: Environmental management, management, lubricating oil, fuel stations, waste, packaging. 


\section{INTRODUÇÃO}

A distribuição e revenda de combustível no Brasil, com data de início em 1912, estão associadas com atividades de exploração e produção de petróleo (MASCARENHAS, 2004). A primeira bomba de gasolina instalada no país foi executada pelas empresas Esso, na cidade do Rio de Janeiro em 1921 e, atualmente, os combustíveis comumente comercializados são: Gás Natural Veicular (GNV), Gasolina automotiva, Óleo Diesel, Óleo lubrificante mineral o etanol (SORATO et al., 2012).

Segundo Barros (2006) os postos não comercializam apenas combustíveis e seus derivados, agregou-se outros valores à seu espaço territorial, onde vários outros serviços são fornecidos aos consumidores, tendo como consequência desta nova função econômica, uma complexidade ambiental mais ampla, que gera mais resíduos sólidos, efluentes líquidos, entre outros.

Os postos de combustíveis abrangem o segmento empresarial de venda a varejo de combustíveis, e segundo Lorenzett e Rossato (2010), estão divididos em duas categorias, os postos cidade e os postos estrada, que atendem a população urbana e que atendem os viajantes e caminhoneiros, respectivamente, sendo que esses últimos possuem instalações relativamente maiores que os demais, em função do publico alvo. Os postos de combustíveis em geral desenvolvem as seguintes atividades: Armazenamento e venda de combustível; lavagem e abastecimento de veículos; troca de óleos e filtros; lubrificação; loja de conveniência; e tratamento dos efluentes líquidos gerados.

Segundo Oliveira et al. (2008), são vários os tipos de resíduos gerados, e que necessitam de cuidados especiais em seu destino final, um exemplo são as embalagens plásticas contaminadas com óleo lubrificante, sendo considerados um dos maiores problemas de destaque na gestão de resíduos sólidos, pois as embalagens contêm resíduos oleosos que dificultam e tornam mais oneroso o processo de reciclagem. Sendo que, o próprio plástico é feito de materiais que se degradam muito lentamente, chegando a um tempo de biodegradação superior a cem anos, além disso, quando queimados produzem gases tóxicos prejudiciais a saúde humana e ambiental (CARASCHI e LEÃO, 2002).

Lorenzett e Rossato (2010) enfatizam a importância da gestão de resíduos nesse segmento empresarial, pois consideram a atividade altamente perigosa ao meio ambiente, em função das intensas relações que ela apresenta com os compartimentos água, solo e ar. Essas relações podem, em caso da ocorrência de acidentes, comprometer a qualidade dos recursos hídricos superficiais e subterrâneos, provocando impactos ambientais, prejudicando a fauna e a flora, e pondo em risco a saúde humana.

Dentre os principais resíduos destaca-se o óleo lubrificante usado, que quando é lançado diretamente no ambiente (em meio hídrico, nas redes de esgotos e solo) ou quando queimados de forma não controlada provocam graves problemas de poluição do solo, das águas e do ar. Quando lançados no solo, infiltram conjuntamente com a água da chuva contaminando o solo e, ao atingirem o lençol freático, poluem também as águas de fontes e poços (SILVEIRA et al., 2006).

Por serem derivados do petróleo, os óleos lubrificantes, sintéticos ou não, apresentam alta viscosidade e longas cadeias de hidrocarbonetos alifáticos e aromáticos empregados em fins automotivos ou industriais, na qual, após o período de uso recomendado pelos fabricantes dos equipamentos, deterioram-se parcialmente, formando compostos oxigenados, compostos aromáticos polinucleares, resinas e lacas (HILIGOSS e O'LEAR, 2001). Em sua constituição existem também os metais de desgaste dos motores e das máquinas lubrificadas e os produtos químicos que, por vezes, são de forma imprudente, adicionados ao óleo e seus contaminantes característicos (BROWN, 1983; EKANEM et al., 1997). A queima indiscriminada, sem tratamento prévio de desmetalização, gera emissões significativas de óxidos metálicos além de outros gases tóxicos, como dioxina e óxidos de enxofre (BORIM e POPP, 2004).

O comércio varejista de combustíveis está submetido à legislação ambiental desde 1981, através da Lei Federal $n^{\circ}$ 6.938, que foi regulamentada pelo Decreto Federal n. ${ }^{\circ} 99.274 / 90$. Essa atividade foi considerada sujeita ao licenciamento ambiental pela Resolução do Conselho Nacional do Meio Ambiente - CONAMA n ${ }^{\circ}$ 237, (BRASIL, 1997), e mais recentemente regulamenta e padronizada pela Resolução CONAMA 273 (BRASIL, 2000), alterada pelas Resoluções CONAMA n 276 (BRASIL, 2001) e $n^{\circ} 319$ (BRASIL, 2002) sendo norma ambiental competente que regulamenta, a nível federal, o licenciamento ambiental para postos de abastecimento, sistemas retalhistas, posto revendedor e posto flutuante (LORENZETT, 2010).

No estado de Goiás a instrução Normativa Nº 07 (SEMARH, 2011) estabelece os critérios e os procedimentos sobre o gerenciamento e disposição final dos resíduos sólidos gerados em unidades de produção industrial, o que inclui os postos de combustíveis. A mesma leva em consideração o que 
dispõe as leis federais, como a Política Nacional de Resíduos 12.305 (Brasil, 2010) e leis estaduais sobre resíduos sólidos industriais. Considera também a NBR 10.004 (ABNT, 2004) que trata da classificação, a resolução CONAMA 313 (BRASIL, 2002) que classifica o resíduo gerado no estabelecimento como perigoso ("Classe I"), estabelecendo assim os critérios de classificação, segregação, acondicionamento e destinação desses resíduos. A resolução estabelece ainda que todo empreendimento gerador de resíduos é responsável pelo recolhimento de seus resíduos, enquadrando-se assim as embalagens plásticas. Nesse trabalho, além de tais leis e resoluções citadas anteriormente, também será considerado a resolução CONAMA 362 (BRASIL, 2005) alterada pela resolução CONAMA 450 (BRASIL, 2012) que trata da disposição do óleo lubrificante usado.

Guidoni (2005) afirma que o descarte inadequado dos resíduos sólidos dos postos de combustíveis é um problema que assume grandes proporções. Os aterros sanitários não podem receber estes resíduos visto que a contaminação com o solo seria imediata. A alternativa para esses resíduos seria a reciclagem e em alguns casos, quando necessário, seria a incineração. Afirma ainda que, nem sempre a destinação correta é viável para os postos revendedores visto que falta infraestrutura em grande parte do país.

Sabendo-se que o descarte de óleos lubrificantes automotivos usados e de embalagens plásticas é uma realidade comum na rotina de trabalho dos funcionários de postos de gasolina e oficinas, algumas perguntas surgem (SILVA e OLIVEIRA, 2011). Sendo assim o presente trabalho tem como objetivo avaliar a gestão do descarte do óleo lubrificante e sua embalagem em postos de combustíveis do município de Terezópolis de Goiás - GO.

\section{MATERIAIS E MÉTODOS}

Esse trabalho utiliza-se de uma abordagem qualitativa, que para Richardson (2008), é a tentativa de se entender a natureza do problema estudado, através da observação e descrição, tendo por objeto situações ou estritamente particulares, sem utilizar procedimentos experimentais e estatísticos para a análise do problema, o que imprime certo teor de subjetivismo à pesquisa. $\mathrm{O}$ autor afirma ainda que o questionário é um instrumento de pesquisa que deve reunir condições tais como: clareza, precisão e objetividade. As questões formuladas devem ser delimitadas a uma dimensão viável, sendo claras, precisas e objetivas (SALOMON, 1999; GIL, 1993). Pode-se citar diversos autores que realizaram pesquisas sobre postos de combustíveis, na qual, também utilizaram este instrumento para coleta de dados sobre a gestão do óleo lubrificante usado e sua embalagem (SILVA e OLIVEIRA, 2011) e gestão de resíduos em geral gerados no empreendimento (GROBERIO et al., 2003; SILVA, 2004; GRECCO et al., 2005; CAMARGO et al., 2007; VENÂNCIO et al., 2008; CATUNDA, 2009; ANDRADE et al., 2011; VIVA e SILVA, 2012).

A área de estudo foi o município de Terezópolis de Goiás, criado em 29/04/1992 pela Lei Estadual n 11.704 (GOIÁS, 1992). A área, desmembrada do município de Goianápolis, está localizada as margens da BR 153, tendo toda a malha rodoviária asfaltada e com pista dupla (Figura 1). Sua população é de 1.561 habitantes com uma área de $106,9 \mathrm{~km}^{2}$, localizada entre dois grandes centros urbanos, Goiânia, a capital de Goiás, e Anápolis, a maior cidade do interior do Estado (IBGE, 2013).

Os dados foram coletados por meio de questionários (Anexo1) com perguntas baseadas e fundamentadas nas exigências impostas pela legislação vigente quanto à disposição final do óleo lubrificante e a embalagem plástica proveniente do mesmo, assim como realizado no trabalho de Silva e Oliveira (2011). Os questionários foram aplicados aos responsáveis de cada estabelecimento, critério esse também utilizado na pesquisa realizada por Catunda (2009) e Grobério et al. (2003).

A coleta de dados foi iniciada no mês de janeiro de 2014, com visitas in loco em que objetivou a apresentação da pesquisa aos responsáveis dos postos de combustível e se o mesmo oferecia o serviço de troca de óleo. Após esta etapa foi verificado a disponibilidade do responsável para participação da pesquisa e em seguida realizada a aplicação do questionário, juntamente com a observação direta do procedimento e levantamento fotográfico.

O questionário foi aprovado no Comitê de ética da UFG (Universidade Federal de Goiás) sob o parecer $n^{\circ} 693.984$ de 2014, sendo o levantamento das informações obtidas foram analisados junto à legislação pertinente. 


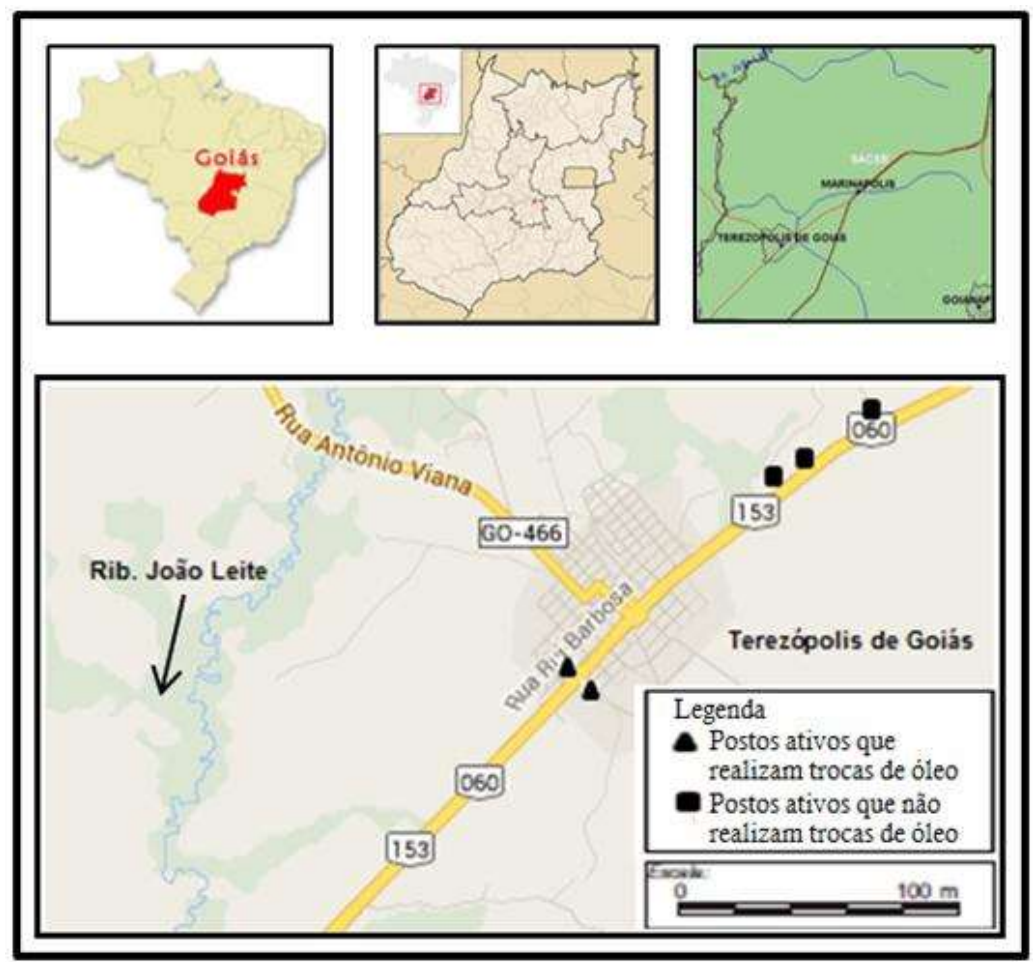

Figura 1 - Mapa de localização dos postos de combustíveis no município de Terezópolis de Goiás (fonte: Google Earth).

\section{RESULTADOS E DISCUSSÃO}

Segundo a Agência Nacional do Petróleo, Gás Natural e Biocombustíveis (ANP), em 2014 existiam 11 postos cadastrados como revendedor de combustível automotivo no município de Terezópolis de Goiás. Após visita in loco, verificou-se que 5 postos de combustíveis estavam ativos, sendo que 2 deles ofereciam os serviços de troca de óleo, gerando o óleo lubrificante usado e suas embalagens. Constatou-se também que alguns postos não estavam localizados nos endereços divulgados pela ANP.

Inicialmente os entrevistados foram questionados sobre qual a quantidade de óleo lubrificante usado e suas embalagens eram produzidos, possibilitando a quantificação dos resíduos contaminados gerados. Observou-se que o município produz $1.400 \mathrm{~L} /$ semestre de óleo lubrificante usado e a mesma quantidade de unidades de embalagens plásticas contaminadas.

Quando perguntados se as embalagens plásticas são armazenadas para reciclagem, os responsáveis afirmaram que realizavam o procedimento, porém um dos estabelecimentos não deixava as embalagens em repouso, procedimento que é recomendado com o objetivo de promover a redução de resíduo contido na embalagem. A coleta e destinação final desse resíduo são realizadas pela prefeitura, encaminhando ao aterro controlado (classificação SEMARH, 2009) do munícipio sem que haja tratamento antes da disposição, podendo contaminar o ambiente devido ao óleo lubrificante usado, remanescente no frasco. Fato esse também observado por Neves (2010), em estudo realizado em postos de combustíveis, funilarias e estabelecimentos de lavagem automotiva do município de São Carlos (Estado de São Paulo - Brasil), apenas uma pequena fração dos estabelecimentos entrevistados realizam a destinação correta desse resíduo, além disso, eram misturados aos resíduos domésticos inviabilizando uma possível reciclagem, não obedecendo às exigências da resolução CONAMA 313 (BRASIL, 2002) que classifica as embalagens que contenham substâncias tóxicas como resíduo perigoso.

A atividade de descarte indevido dessas embalagens no aterro controlado do município apresenta um grande risco para a qualidade da água da região e consequentemente da saúde humana, visto que, como afirma os autores Martins e Silva (2013), o município assim como seu aterro controlado está inserido nas abrangências da área de preservação ambiental (APA) João Leite que protege a bacia do Ribeirão João Leite responsável pelo abastecimento de água do município de Goiânia e outros adjacentes. 
Martins e Silva (2013) em seu trabalho apresentam também, uma possível justificativa para o fechamento de um dos postos de combustíveis de Terezópolis de Goiás, que foi desapropriado pelo governo por apresentar seus tanques subterrâneos em um nível abaixo da cota máxima do lago da bacia do João Leite, e estar numa área que seria necessária a elevação da pista da BR-153, posto este que quando visitado para a aplicação do questionário encontrava-se inativo.

Quando questionados se os recipientes para armazenamento do óleo usado e suas embalagens foram cedidos pela empresa coletora, a resposta foi unânime, afirmando que os recipientes foram providenciados pelos próprios estabelecimentos o que reforça o fato já observado em outro trabalho, na qual todos os postos entrevistados adquiriram em outros estabelecimentos os recipientes para armazenamento (SILVA e OLIVEIRA, 2011).

Segundo Gerhardt et al. (2013) os recipientes de armazenamento de óleo lubrificante usado deve apresentar boas condições podendo ser utilizados latões, bombonas e tanques. As bombonas plásticas se destacam devido a facilidade de manuseio e sua resistência. Nos 2 postos estudados são utilizados tanques subterrâneos (Figura 2) para este fim, enviando-os para a reciclagem, como exige a Resolução CONAMA 362 (Brasil, 2005), que dispõe sobre o recolhimento, coleta e destinação final de óleo lubrificante usado ou contaminado, estabelecendo em seu Art. $3^{\circ}$ que todo o óleo lubrificante usado ou contaminado coletado deverá ser destinado à reciclagem por meio do processo de rerrefino.

Assim como os resultados encontrados por Lima e Cabral (2010) e GERHARDT et al. (2013) o óleo é coletado por uma empresa licenciada pelo órgão ambiental, sendo que a frequência da coleta varia de mensal a bimensalmente nos postos analisados. De acordo com os entrevistados as empresas que realizam a coleta do óleo compram o material, resultado esse observado também por Silva e Oliveira (2011).

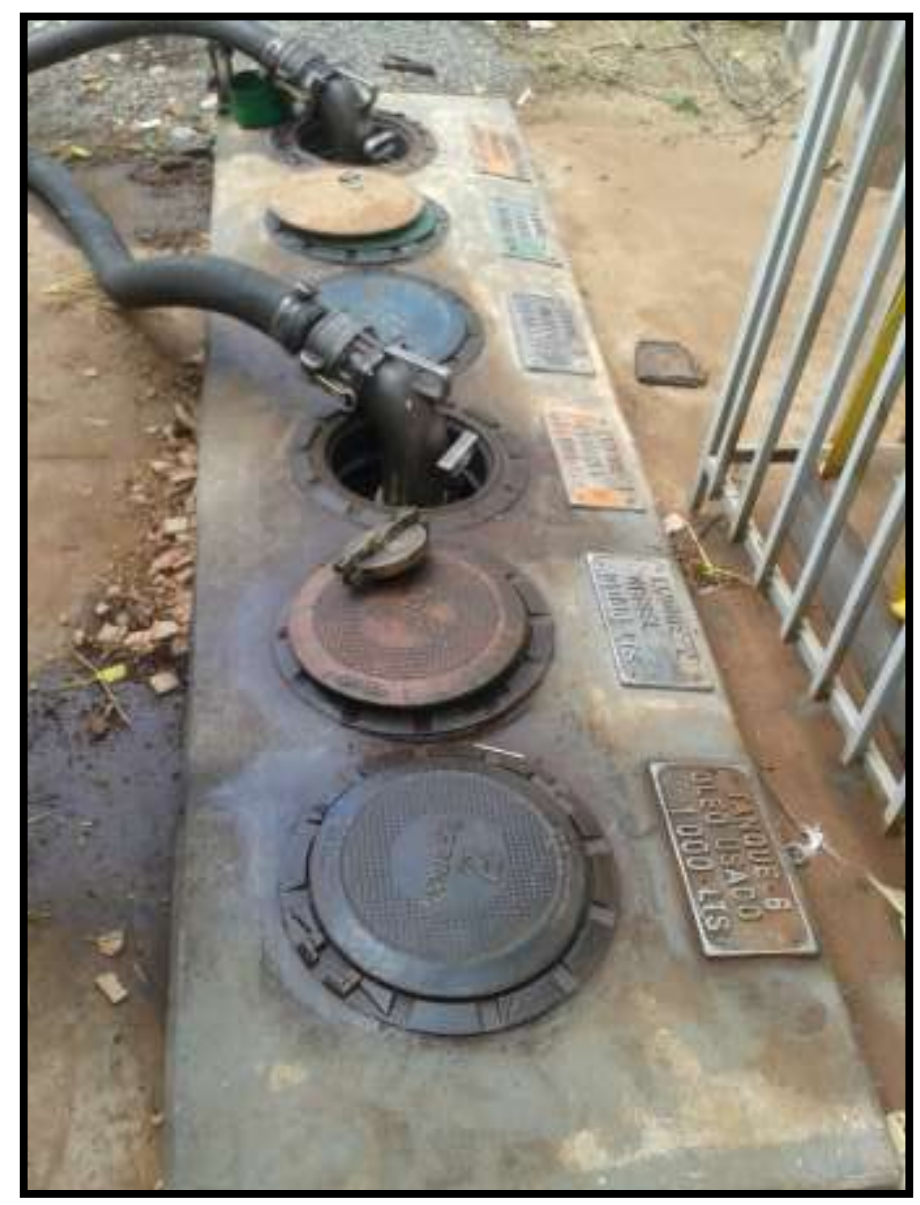

Figura 2 - Tanque subterrâneo que armazena o óleo lubrificante usado em um dos estabelecimentos entrevistados, no município de Terezópolis de Goiás - GO. 
Ao serem questionados quanto aos materiais contaminados gerados durante a troca de óleo (pano, serragem, etc), todos os entrevistados afirmaram que o material impregnado é misturado com o lixo comum e enviado ao aterro controlado. Apesar de existir fiscalização em tais estabelecimentos, como afirma Camargo et al. (2007), ainda há ineficiência em sua abrangência, visto que as atenções são voltadas apenas para o óleo, deixando o descarte dos resíduos sólidos a critério da empresa.

Foi possível observar que em todos os postos analisados os gerentes afirmaram que os seus funcionários já passaram por um treinamento aplicado por empresas especializadas no que tange o descarte desses materiais e, quando indagados se tinham conhecimento sobre a legislação, quanto ao descarte das embalagens usadas e do óleo usado, todos responderam positivamente, afirmando que gostariam de maiores informações sobre o assunto e que tinham conhecimento dos impactos provocados ao meio ambiente por descartes inadequados, resultados esses também observados por Silva e Oliveira (2011) em sua pesquisa.

Todos os entrevistados afirmaram que seus estabelecimentos passam por frequente fiscalização ambiental, contabilizando até uma visita mensalmente. Esse fator se deve a preocupação que o governo tem com o funcionamento dos postos de combustíveis que comercializam substâncias altamente contaminantes, podendo oferecer risco ao meio ambiente. O que corrobora as ideias apresentadas por Nóbrega (2009) quando afirma que por se tratar de postos distribuidores de combustível em área urbana fica evidente que sem fiscalização rígida pode ocorrer acidentes e danos ao meio ambiente, bem como à sociedade diretamente.

Todos os postos de combustíveis apresentavam caixa separadora de água e óleo, aspecto esse também observado em outros trabalhos, no qual todos ou a maioria dos estabelecimentos possuíam caixa separadora (NEVES, 2010; SILVA e OLIVEIRA, 2011). Esse sistema é de extrema importância devido as suas características que comprometem a qualidade do efluente quando lançado sem tratamento na rede coletora de esgoto (GERHARDT et al., 2013). Essa estrutura é exigida pela NBR 14.605 (ABNT, 2000), sendo bastante fiscalizada.

\section{CONCLUSÕES}

Através do presente trabalho foi possível concluir que os postos de combustíveis do município de Terezópolis de Goiás ainda não descartam corretamente todos os resíduos gerados pela troca do óleo lubrificante dos veículos que os outros materiais como a embalagem usada, a estopa e a serragem precisam ter outra destinação final que não seja o aterro controlado da cidade, o qual encontra-se em uma APA e sem a devida Licença Ambiental. Talvez com o auxílio do governo criando programas ambientais na região que exija mais atenção para tais resíduos o problema em uma região tão importante ambientalmente seja sanado.

Levando em consideração o interesse dos funcionários sobre o assunto e dos riscos ao meio ambiente envolvidos assim como o fato que os resíduos sólidos de postos de combustíveis serem, em sua maioria, passíveis de reaproveitamento, sugerimos que a elaboração do Plano de Gerenciamento de Resíduos, documento descrito na Lei no 12.305 de 2010 e na IN da SEMARH n ${ }^{\circ} 07$ de 20011 como obrigatório para estes empreendimentos, seja realmente efetivado, uma vez que nele são descritos os procedimentos corretos a serem adotados, desde manejo, acondicionamento, coleta, tratamento e destinação final, que atenda as normas ambientais vigentes, tendo como principal objetivo a redução na geração dos resíduos através do reuso e reciclagem, diminuindo, dessa forma, os impactos no meio ambiente, além de contribuir para a saúde humana, minimizando os custos e danos associados à destinação de tais resíduos.

\section{REFERÊNCIAS}

ABNT - ASSOCIAÇÃO BRASILEIRA DE NORMAS TÉCNICAS. NBR 14.605: Posto de serviço - Sistema de drenagem oleosa. Rio de Janeiro, 2000, 2 p.

ABNT - ASSOCIAÇÃO BRASILEIRA DE NORMAS TÉCNICAS. NBR 10.004: Resíduos Sólidos - Classificação. Rio de Janeiro, 2004. 71 p. 
ANDRADE, C. S.; SOUSA, C. A.; ÉRAS, A. C. S. Indicadores de desempenho ambiental utilizados como ferramenta de gestão no setor de distribuição e revenda de combustíveis. In: Congresso Brasileiro de Gestão Ambiental, 2., 2011, Londrina - PR. Anais... Londrina: IBEAS, 2011. pp. A1.1-A1.8.

ANP - Agência Nacional do Petróleo. Disponível em: <http://www.anp.gov.br/> (Acedido a agosto de 2013).

BARROS, P. E. O. Diagnóstico Ambiental para Postos de Abastecimento de Combustíveis - DAPAC. Dissertação de Mestrado, Universidade do Vale do Itajaí, Centro de Ciências Tecnológicas da Terra e do Mar CTTMAR, 2006.

BORIM, A.; POPPI, R. J. Multivariate quality control of lubricating oils using Fourier transform infrared Spectroscopy. J. Braz. Chem. Soc., v.15 (4), p.570-576, 2004.

Brasil. Conselho Nacional do Meio Ambiente. Resolução no 237 de 19 de dezembro de 1997. Regulamenta os aspectos de licenciamento ambiental estabelecidos na Política Nacional do Meio Ambiente.

.Conselho Nacional do Meio Ambiente. Resolução no 273, 29 de novembro de 2000. Estabelece diretrizes para o licenciamento ambiental de postos de combustíveis e serviços e dispõe sobre a prevenção e controle da poluição.

Conselho Nacional do Meio Ambiente. Resolução nº 276, de 25 de abril de 2001. Prorroga o prazo da Resolução 273/00 sobre postos de combustíveis e sérvios por mais 90 dias.

Conselho Nacional do Meio Ambiente. Resolução no 313, de 29 de Outubro 2002. Dispõe sobre o Inventário Nacional de Resíduos Sólidos Industriais.

. Conselho Nacional do Meio Ambiente. Resolução no 319, de 04 de dezembro de 2002. Dá nova redação a dispositivos da Resolução CONAMA n ${ }^{\circ} 273$, de 29 de novembro de 2000, que dispõe sobre prevenção e controle da poluição em postos de combustíveis e serviços.

Conselho Nacional do Meio Ambiente. Resolução n ${ }^{\circ}$ 362, de 23 de junho de 2005. Dispõe sobre o recolhimento, coleta e destinação final de óleo lubrificante usado ou contaminado.

Conselho Nacional do Meio Ambiente. Resolução no 450, de 06 de março de 2012. Altera os arts. $9^{\circ}$, 16, 19, 20, 21 e 22, e acrescenta o art. 24-A a Resolução no 362, de 23 de junho de 2002, do Conselho Nacional do Meio Ambiente-CONAMA, que dispõe sobre recolhimento, coleta e destinação final de óleo lubrificante usado ou contaminado.

BRASIL. Lei ${ }^{\circ}$ 6.938, de 31 de agosto de 1981, regulamentada pelo Decreto $\mathrm{n}^{\circ}$ 99.274, de 6 de julho de 1990. Dispõe sobre a Política Nacional do Meio Ambiente, seus fins e mecanismos de formulação e aplicação, e dá outras providências.

BRASIL. Lei n ${ }^{\circ}$ 12.305, de 02 de agosto de 2010. Institui a Política Nacional de Resíduos Sólidos no Brasil. Diário Oficial da União, Brasília-DF.

BROWN, R. J. Determination of trace metals in petroleum and petroleum products using an inductively coupled plasma optical emission spectrometer. Spectrochimica Acta Part B: Atomic Spectroscopy, v.38 (1), p. 283-289, 1983.

CATUNDA, A. C. M. M. Diagnóstico para implantação do sistema de gestão ambiental em postos revendedores de combustíveis no município de Paranamirim - RN: Um estudo de caso. Dissertação de Mestrado em Engenharia de produção, Universidade Federal do Rio Grande do Norte, Paranamirim, 2009.

CAMARGO, P. F. T.; SOUZA, L. L.; FONSECA, G. B.; TEMPONI, S. S.; CIRILO F. D.; FONTENELLE, J. R. Conscientização sobre o descarte de óleos automotivos em postos de gasolina de Ouro preto - Minas 
Gerais. In: Congresso de Ecologia do Brasil, VIII, 2007, Caxambú - MG. Anais... Caxambú: USP, 2007. pp. 2.

CARASCHI, J. C.; LEÃO, A. L. Avaliação das propriedades mecânicas dos plásticos reciclados provenientes de resíduos sólidos urbanos. Acta Scientiarum, v. 24(6), p.1599-1602, 2002.

EKANEM, E. J.; LORI J. A.; THOMAS, S. A. The determination of wear metals in used lubricating oils by flame atomic absorption spectrometry using sulphanilic acid as ashing agent. Talant, v. 44 (11), p.2103$2108,1997$.

GERHARDT, A. E.; DRUMM, F. C., GRASSI, P.; FLORES, B. A.; PASSINI, A. C. F.; BORBA, W. F.; KENERICH, P.D.C. Diagnóstico para o gerenciamento dos resíduos sólidos em oficina mecânica: estudo de caso em concessionária do município de Frederico Westphalen-RS. Revista Monografias Ambientais, v. 13, n. 1, p. 2899-2908, 2013.

GIL, A. C. Como elaborar projetos de pesquisa. Atlas. São Paulo, Brasil, 1993.

Goiás. Lei Estadual n 11.704 de 29 de abril 1992. Dispõe sobre a criação do Município de Terezópolis de Goiás e dá outras providências. Diário Oficial da União, Goiás-Brasil, 30 de abril de 1992.

Google Earth maps. http://mapas.google.com (Acessado em outubro de 2012).

GRECCO, L. B.; MACEDO, S. R. K.; BARRETO, E. M. S.; VERONEZ, F. A. Proposta de plano unificado de gerenciamento de resíduos sólidos para postos revendedores de combustíveis do estado do Espírito Santo. In: Congresso Brasileiro de Engenharia Sanitária e Ambiental, 23., 2005, Campo Grande - MS, Anais... Campo Grande: ABES, 2005 pp. 8.

GROBERIO, F.; BRAGA, F. S.; SOUZA, M. R.; BERTOLDE, A. J. Caracterização de resíduos sólidos, oleosos de postos de serviço automotivo da cidade de Vitória - ES. In: Congresso Brasileiro de Engenharia Sanitária e Ambiental, 22., 2003, Joinville - SC. Anais...Joinville: ABES, 2003. pp. 25.

HILIGOSS, D.; O'LEAR D. Analysis of wear metals and additive package elements in new and used oil using the optima 4300 DV ICP-OES. Atomic Spectroscopy. v.22 (2), p. 276-279, 2001.

IBGE - Instituto Brasileiro de Geografia e Estatística (2013). http://www.ibge.gov.br/.(acessado em 12 de dez. de 2013).

LIMA, A. S.; CABRAL, A. E. B. Diagnóstico para implantação de plano de gerenciamento de resíduos sólidos em um posto de combustível na cidade de Fortaleza - CE. In: Seminário da região nordeste sobre resíduos sólidos, 2., 2010, João Pessoa. Anais... João Pessoa: [s.n.], 2010. p. 01-09.

LORENZETT, D. B.; ROSSATO M. V. A gestão de resíduos em postos de abastecimento de combustíveis. Revista Gestão Industrial, v. 6 (2), p.110-125, 2010.

LORENZETT, D. B. gestão ambiental em postos de combustíveis. In: Simpósio de ensino, pesquisa e extensão. Anais... Santa Maria: Unifra, 2010. 10pp.

MARTINS, M. A.; SILVA, M.A. A construção da barragem João Leite e os reflexos nas áreas de abrangência do reservatório. In: Congresso Brasileiro de Gestão Ambiental, 4., 2013; Salvador -BA. Anais...Salvador: IBEAS, 2013. pp. A1.1-A1.9.

MASCARENHAS, F. A. B. A proteção Ambiental nas atividades de distribuição e revenda de combustíveis. Pensar, v.9 (9), p.54-70, 2004.

GUIDONI, Rosemeire. A solução é inverter a pirâmide. Revista Combustíveis \& Conveniência . São Paulo: 
ed. 40, 2007.

NEVES, A. A. C. Estudo sobre resíduos sólidos em postos de combustíveis, funilarias e estabelecimentos de lavagem automotiva do município de São Carlos, usando indicadores de sustentabilidade. Tese de doutorado em Engenharia Ambiental, Universidade de São Paulo. São Carlos, Brasil, 2010.

NÓBREGA, R. S. Impactos ambientais causados pelos postos de combustíveis em Porto Velho (RO): Análise da vistoria técnica para obtenção de licenças ambientais. Revista Brasileira de Gestão Ambiental, v.3 (1), p. 13-22, 2009.

OLIVEIRA, V.B.P.; GOMES, P.L.; NASCIMENTO, E.A. Estratégias ambientais em postos de combustíveis: O caso de posto de combustível ecológico. In: Congresso Nacional de Excelência em Gestão, 4., 2008, Niterói - RJ. Anais...Niterói: 2008. 18pp.

RICHARDSON, R. J. Pesquisa social: métodos e técnicas. 3. ed. Atlas. São Paulo, Brasil, 2008.

SALOMON, D. V. Como fazer uma monografia. Fontes. São Paulo, Brasil, 1999.

SEMARH. Secretaria de estado do meio ambiente e dos recursos hídricos de Goiás. Diagnóstico do Monitoramento dos Sistemas de Disposição do Lixo Urbano nos Municípios Goianos. Goiânia, 2009.

SEMARH. Secretaria de estado do meio ambiente e dos recursos hídricos. Instrução Normativa ${ }^{\circ} 07$, de 10 de agosto de 2011. Dispõe sobre gerenciamento e disposição final dos resíduos sólidos gerados em unidades de produção industrial, de bens e serviços.

SILVA, E. F. Gestão ambiental dos postos revendedores de combustíveis no estado do Rio de Janeiro: Uma avaliação crítica na visão ocupacional e ambiental da presença do benzeno na gasolina automotiva. Dissertação de Mestrado profissional em Sistemas de gestão, Universidade Federal Fluminense, Niterói. Rio de Janeiro, 2004.

SILVA, T. A.; OLIVEIRA, K. M. Descarte de óleos lubrificantes e suas embalagens: Estudo de caso dos postos de gasolina e oficinas da cidade de Ituiutaba, Estado de Minas Gerais. OBSERVATORIUM: Revista Eletrônica de Geografia, v.3 (7), p.101-114, 2011.

SILVEIRA, E. L. C.; CALAND, L. B.; MOURA, C. V. R. Determinação de contaminantes em óleos lubrificantes usados em esgotos contaminados por esses lubrificantes. Química Nova, v.29, p. 1193-1197, 2006.

SORATO, K. A. D. L.; PORTON, R. A. B.; FRASSAO, E.; CITTADIN, A. Identificação de itens de natureza ambiental: Um estudo de caso em um posto de combustível. In: Congresso Brasileiro de Contabilidade, 19., 2012, Belém-PA. Anais eletrônicos... Belém. pp. 7. 2012.

VENÂNCIO, T.L.; VIDAL, C.M.S.; MOISA, E. Avaliação da percepção da importância da gestão ambiental em postos de combustíveis localizados na cidade de Irati, Paraná. Ambiência - Revista do Setor de Ciências Agrárias e Ambientais, v. 4 (3), p.27-33, 2008.

VIVA, M. T.; SILVA, V. B. Gestão de resíduos em postos de combustíveis. Monografia para o curso de bacharelado em administração. Faculdade de Pindamonhangaba. São Paulo, 2012. 


\section{ANEXO 1 - QUESTIONÁRIO: LEVANTAMENTO DE INFORMAÇÕES 1 - GESTÃO DO ÓLEO LUBRIFICANTE USADO E SUAS EMBALAGENS}

\begin{tabular}{|c|c|}
\hline $\begin{array}{l}\text { 1.1 Qual a quantidade do resíduo gerado do óleo } \\
\text { lubrificante usado e das suas embalagens? } \\
1.2 \text { As embalagens dos óleos lubrificantes automotivos } \\
\text { são armazenadas para a reciclagem? }\end{array}$ & $\begin{array}{l}\text { ( ) Sim } \\
\text { ( ) Não }\end{array}$ \\
\hline $\begin{array}{l}1.3 \text { Como é o recipiente para armazenamento deste } \\
\text { resíduo? }\end{array}$ & $\begin{array}{l}\text { ( ) Tambor de plástico } \\
\text { ( ) Caixa de madeira } \\
\text { ( ) Caixa de papelão } \\
\text { ( ) A granel } \\
\text { ( ) Outra, qual? }\end{array}$ \\
\hline 1.4 As embalagens são deixadas em repouso? & $\begin{array}{l}\text { ( ) Sim } \\
\text { ( ) Não }\end{array}$ \\
\hline $\begin{array}{l}\text { 1.5 Os recipientes para armazenamento do óleo usado } \\
\text { e suas embalagens foram cedidos pela empresa } \\
\text { coletora? }\end{array}$ & $\begin{array}{l}\text { ( ) Sim } \\
\text { ( ) Não }\end{array}$ \\
\hline $\begin{array}{l}1.6 \text { O estabelecimento possui caixa de separação para } \\
\text { água e óleo? }\end{array}$ & $\begin{array}{l}\text { ( ) Sim } \\
\text { ( )Não }\end{array}$ \\
\hline $\begin{array}{l}1.7 \text { O óleo lubrificante automotivo usado é coletado e } \\
\text { destinado à reciclagem? }\end{array}$ & $\begin{array}{l}\text { ( ) Sim } \\
\text { ( ) Não }\end{array}$ \\
\hline 1.8 A coleta é feita com qual frequência? & $\begin{array}{l}\text { ( ) Semanal } \\
\text { ( ) Quinzenal } \\
\text { ( ) Mensal } \\
\text { ( ) Bimensal } \\
\text { ( ) Outra/ Qual?. }\end{array}$ \\
\hline $\begin{array}{l}1.9 \text { A empresa coletora compra o óleo usado e as } \\
\text { embalagens. }\end{array}$ & $\begin{array}{l}\text { ( ) Sim } \\
\text { ( ) Não }\end{array}$ \\
\hline $\begin{array}{l}1.10 \text { O material contaminado utilizado na limpeza } \\
\text { (pano, serragem, areia) é encaminhado para o lixo } \\
\text { comum? }\end{array}$ & $\begin{array}{l}\text { ( ) Sim } \\
\text { ( ) Não }\end{array}$ \\
\hline $\begin{array}{l}1.11 \text { Já houve algum treinamento formal sobre o } \\
\text { descarte destes materiais? }\end{array}$ & $\begin{array}{l}\text { ( ) Sim } \\
\text { ( ) Não }\end{array}$ \\
\hline $\begin{array}{l}1.12 \text { Você tem conhecimento sobre a legislação quanto } \\
\text { ao descarte de embalagens usadas de óleo lubrificante? }\end{array}$ & $\begin{array}{l}\text { ( ) Sim } \\
\text { ( ) Não }\end{array}$ \\
\hline $\begin{array}{l}1,13 \text { Você se interessaria em obter mais informações } \\
\text { sobre práticas mais adequadas em seu trabalho, em } \\
\text { relação ao descarte dos resíduos gerados? }\end{array}$ & $\begin{array}{l}\text { ( ) Sim } \\
\text { ( ) Não }\end{array}$ \\
\hline $\begin{array}{l}\text { 1.14 A empresa já foi fiscalizada por algum órgão } \\
\text { ambiental? }\end{array}$ & $\begin{array}{l}\text { ( ) Sim } \\
\text { ( ) Não }\end{array}$ \\
\hline $\begin{array}{l}\text { 1.15 Você tem conhecimento dos impactos provocados } \\
\text { ao meio ambiente pelo descarte inadequado do óleo } \\
\text { lubrificante usado e das embalagens? }\end{array}$ & $\begin{array}{l}\text { ( ) Sim } \\
\text { ( ) Não }\end{array}$ \\
\hline
\end{tabular}

